\title{
Avaliação de acessos de feijão-fava, para resistência a Colletotrichum truncatum, em condições de folhas destacadas e campo
}

\author{
Mara Danielle Silva do Carmo ${ }^{1}$, Eulália Maria Sousa Carvalho², Regina Lucia Ferreira Gomes ${ }^{2}$, Ângela Celis de \\ Almeida Lopes ${ }^{2}$, Gerusa Rodrigues dos Santos Cavalcante ${ }^{2}$
}

\begin{abstract}
${ }^{1}$ Universidade Estadual do Piauí, Campus Prof. Barros Araújo, BR 316, KM 299, Bairro Altamira, CEP 64602-000, Picos, PI; ${ }^{2}$ Universidade Federal do Piauí (UFPI), Campus Universitário Ministro Petrônio Portella, Ininga, CEP: 64049-550, Teresina, PI

Autor para correspondência: Eulália Maria Sousa Carvalho (eulaliamsc@yahoo.com.br)

Data de chegada: 03/03/2015. Aceito para publicação em: 10/09/2015.
\end{abstract}

$10.1590 / 0100-5405 / 2079$

\section{RESUMO}

Carmo, M.D.S.; Carvalho, E.M.S.; Gomes, R.L.F.; Lopes, A.C.A.; Cavalcante, G.R.S. Avaliação de acessos de feijão-fava, para resistência a Colletotrichum truncatum, em condições de folhas destacadas e campo. Summa Phytopathologica, v.41, n.4, p.292-297, 2015.

O feijão-fava (Phaseolus lunatus L.) tem se mostrado uma importante fonte alternativa de alimentação e renda para as populações mais carentes na região Nordeste do Brasil. Entretanto, vários fatores, dentre eles a ocorrência de doenças têm contribuído para o baixo rendimento da cultura. Assim, no presente trabalho objetivou-se avaliar a reação de doze acessos de feijão-fava, de hábito de crescimento determinado, ao agente causal da antracnose, Colletotrichum truncatum, em condições de folha destacada, inoculada com o fungo e campo, sem inoculação. A severidade da doença foi estimada através de escala de notas e os acessos foram agrupados em cinco classes de acordo com a resistência. Os acessos apresentaram resistência variável à antracnose, de acordo com as condições de cultivo, sendo que em folhas destacadas foram mais suscetíveis ao fungo do que no campo. Observou-se no campo, para a maioria dos acessos, redução na porcentagem de área foliar doente em comparação com as respostas apresentadas em folha destacada. Os acessos UFPI 641, UFPI 644 e UFPI 645 comportaram-se como moderadamente resistentes em folha destacada, aos sete dias após a inoculação. Estes genótipos são, portanto, promissores para serem utilizados em programas de melhoramento genético do feijão-fava.

Palavras-chave: Phaseolus lunatus, antracnose, fitopatógeno, inoculação.

\section{ABSTRACT}

Carmo, M.D.S.; Carvalho, E.M.S.; Gomes, R.L.F.; Lopes, A.C.A.; Cavalcante, G.R.S. Evaluation of lima bean accessions for resistance to Colletotrichum truncatum under conditions of detached leaves and in the field. Summa Phytopathologica, v.41, n.4, p.292-297, 2015.

The lima bean (Phaseolus lunatus L.) has become an important alternative source of food and earnings to low-income populations in the Northeast Region of Brazil. However, several factors have contributed to the low yield of this crop, such as occurrence of diseases. Thus, the present study aimed to assess the reaction of twelve lima bean accessions, of determined growth habit, to the causal agent of anthracnose, Colletotrichum truncatum, under conditions of detached leaves inoculated with the fungus and in the field without inoculation. The severity of the disease was estimated by means of a score scale and the accessions were grouped into five classes according to resistance. The accessions had variable resistance to anthracnose according to the growth conditions. Detached leaves were more susceptible to the fungus than those in the field. For most accessions in the field, there was a reduction in the percentage of diseased leaf area, compared to the responses shown by detached leaves. The accessions UFPI 641, UFPI 644 and UFPI 645 behaved as moderately resistant for detached leaves at seven days after inoculation. These genotypes are, therefore, promising for breeding programs of lima beans.

Additional key-words: Phaseolus lunatus, anthracnose, phytopathogen, inoculation.

O feijão-fava (Phaseolus lunatus L.) tem se mostrado uma importante fonte alternativa de alimentação e de renda para as populações mais carentes, fornecedora de proteína, especialmente na região Nordeste do Brasil (33). O seu cultivo é feito tradicionalmente por pequenos agricultores, os quais se utilizam predominantemente de variedades crioulas de crescimento indeterminado. Esta característica requer a prática do tutoramento, feita geralmente pelo plantio do feijãofava em consórcio com culturas que oferecem suporte, como o milho; tal prática dificulta a colheita mecanizada e ocupa a área por mais tempo, gerando maiores gastos com mão-de-obra, além disso, nem sempre está associada a maiores rendimentos $(1,23,26)$.

Além da ausência de tecnologias, a ocorrência de doenças e pragas é um importante fator que contribui para o baixo rendimento da cultura $(2,31,33)$. A antracnose, causada pelo fungo Colletotrichum truncatum (Schweinitz) Andrus \& W. D. Moore, destaca-se entre as doenças fúngicas que tem prejudicado grandemente culturas de importância econômica (12). No caso do feijão-fava ocorre uma redução na produção e qualidade de vagens e grãos prejudicando a comercialização.

Os principais sintomas da antracnose no feijão-fava são lesões em 
forma de cratera nas vagens, com coloração marrom-escura e bordas vermelho-arroxeadas. Lesões em forma de manchas avermelhadas podem ser observadas também inicialmente nas nervuras da parte inferior das folhas, resultando em folhas encarquilhadas e plantas subdesenvolvidas, bem como sobre hastes, pecíolos jovens e hipocótilo (25). O fungo pode ainda sobreviver em sementes e restos da cultura durante aproximadamente dois anos $(9,24)$.

A resistência genética é uma das ferramentas promissoras para o controle de doenças em diversos patossistemas $(10,19,32)$. Esta forma de controle, no entanto, é um processo complexo devido à grande variabilidade fisiológica dos fungos patogênicos, inclusive os do gênero Colletotrichum $(20,28,32)$, gerando a necessidade de uma contínua procura por materiais resistentes $(4,29)$.

Além da superação de problemas de resistência a determinados estresses bióticos, como patógenos, existe a demanda por cultivares mais produtivas e com arquitetura que facilite os tratos culturais, o que beneficiaria tanto empresários rurais como agricultores familiares (27, $28,30)$. Deste modo, no presente trabalho, objetivou-se avaliar a reação de doze acessos de feijão-fava de hábito de crescimento determinado a Colletotrichum truncatum, em condições de folha destacada, inoculadas com o fungo e campo, sem inoculação.

\section{MATERIAL E MÉTODOS}

A reação das subamostras de feijão-fava à antracnose foi avaliada em condições de laboratório, empregando-se folhas destacadas e, em plantas, ao nível de campo, no Centro de Ciências Agrárias (CCA) da Universidade Federal do Piauí (UFPI), em Teresina, Piauí, com localização a $05^{\circ} 02^{\prime} 45^{\prime}$ 'S e $42^{\circ} 46^{\prime} 57^{\prime}$ 'W. Foram avaliadas doze subamostras de feijão-fava de hábito de crescimento determinado, sendo uma procedente do estado da Paraíba e onze introduzidas do Centro Internacional de Agricultura Tropical (CIAT, Colômbia), as quais foram incorporadas ao Banco Ativo de Germoplasma de Feijãofava da UFPI (Tabela 1).

Experimento 1. Reação de feijão-fava a Colletotrichum truncatum em folha destacada

Para a avaliação da severidade da doença em folha destacada, os acessos foram cultivados em casa-de-vegetação, no período de 19 de setembro a 30 de novembro de 2010. Realizou-se o plantio de três sementes em vasos de plástico, contendo $4 \mathrm{~kg}$ de terra vegetal adubada, conforme a análise de solo, deixando-se uma planta por vaso após desbaste. Foram utilizados quatro vasos por acesso.

A avaliação foi realizada em oito folhas trifolioladas completamente expandidas de cada acesso, com 70 dias de idade, as quais foram destacadas das plantas no dia anterior à inoculação. Em seguida, as folhas foram acondicionadas em placa de Petri $(150 \times 20 \mathrm{~mm})$ esterilizadas contendo três lâminas de vidro, uma fina camada de algodão e um disco de papel de filtro umedecido com $20 \mathrm{~mL}$ de água esterilizada, segundo metodologia descrita por Mendes \& Bergamin Filho (21).

O delineamento experimental foi o inteiramente casualizado, com quatro repetições, sendo cada repetição constituída por uma folha trifoliolada.

Para a inoculação, empregou-se o isolado CT4 de C. truncatum, obtido no Laboratório de Fitossanidade do Departamento de Fitotecnia/ CCA/UFPI. O inóculo foi preparado adicionando-se $20 \mathrm{~mL}$ de água destilada esterilizada à placa do fungo cultivado em meio de cultura FDA (feijão, dextrose, ágar) a $28 \pm 1^{\circ} \mathrm{C}$ e fotoperíodo de 12 horas, durante 15 dias, removendo-se os conídios com uma alça de platina em formato "o". Em seguida, a suspensão foi filtrada em filtro de tecido e a concentração ajustada em $10^{5}$ esporos $/ \mathrm{mL}$ com o auxílio da câmara de Neubauer.

A inoculação foi feita pulverizando-se a face superior e inferior da folha com aproximadamente 1,5 $\mathrm{mL}$ da suspensão de conídios (quatro folhas/subamostra) ou água esterilizada para as testemunhas (quatro folhas/subamostra). Após a inoculação, as placas foram fechadas com filme plástico transparente para manter uma umidade elevada. Após 48 horas, em incubadora com temperatura ajustada para $28 \pm 1^{\circ} \mathrm{C}$ e fotoperíodo de 12 horas, o filme plástico foi retirado e as folhas mantidas nessas condições até a avaliação.

A severidade foi avaliada visualmente, por três avaliadores, aos cinco e sete dias após a inoculação (DAI), utilizando-se uma escala de notas variando de 0 a 5, segundo Carvalho (5), sendo: nota $0=$ ausência de sintomas; nota $1=$ traços a $10 \%$ da área foliar infectada; nota $2=$ de 11 a $25 \%$ da área foliar infectada; nota $3=$ de 26 a $50 \%$ da área foliar infectada, sem queda de folíolo; nota $4=$ de 51 a $75 \%$ da área foliar infectada, sem ou com queda de um dos folíolos; nota $5=$ de 76 a $100 \%$ da área foliar infectada, sem ou com queda de dois ou

Tabela 1. Relação das subamostras de feijão-fava avaliadas em Teresina, PI, 2010/2011.

\begin{tabular}{cccc}
\hline Subamostra & Procedência & País de Origem & Cor do tegumento \\
\hline UFPI 728 & Paraíba & Brasil & Creme rajado de castanho escuro \\
UFPI 634 & CIAT & Filipinas & Vermelho rajado de preto \\
UFPI 639 & CIAT & Estados Unidos & Castanho claro rajado de roxo \\
UFPI 640 & CIAT & Trinidad e Tobago & Branco \\
UFPI 642 & CIAT & Gana & Branco \\
UFPI 645 & CIAT & Estados Unidos & Branco \\
UFPI 638 & CIAT & Estados Unidos & Branco \\
UFPI 641 & Estados Unidos & Branco \\
UFPI 632 & CIAT & Estados Unidos & Branco \\
UFPI 635 & CIAT & Índia & Branco \\
UFPI 644 & CIAT & Estados Unidos & Branco \\
UFPI 643 & CIAT & Estados Unidos & Branco \\
\hline
\end{tabular}

${ }^{1}$ CIAT $=$ Centro Internacional de Agricultura Tropical. 
três folíolos. Após a avaliação da severidade, obteve-se a média das notas atribuídas pelos avaliadores para as repetições de cada acesso.

Com base nas médias das notas, os acessos foram então classificados em cinco categorias, de acordo com a reação a C. truncatum, segundo critérios estabelecidos para a cultura do feijão-caupi por Belmino (3): Imune $(\mathrm{IM})=0$; Altamente resistente $(\mathrm{AR})=0,1-1,4$; Moderadamente resistente $(\mathrm{MR})=1,5-2,4$; Moderadamente suscetível $(\mathrm{MS})=2,5-3,0$; Altamente suscetível (AS) = acima de 3,0.

Realizou-se a análise de variância dos dados, após a transformação destes para $\sqrt{\mathrm{x}+1}$. Na comparação entre as médias dos acessos foi utilizado o teste de Duncan $(\mathrm{P}<0,05)$ e na comparação entre as médias das testemunhas com as médias dos seus respectivos tratamentos inoculados, o teste de Dunnet $(\mathrm{P}<0,05)$. As análises foram realizadas com o auxílio do aplicativo Genes (11).

Experimento 2. Reação de feijão-fava a Colletotrichum truncatum em condições de campo

Os acessos de feijão-fava foram cultivados em área experimental do Departamento de Fitotecnia/CCA/UFPI, em Teresina, PI, com histórico de cultivo de feijão-fava e de ocorrência de antracnose, no período 20 de setembro de 2010 a 09 de janeiro de 2011. As condições climáticas referentes a esse período constam na Tabela 2.

Tabela 2. Médias dos elementos climáticos temperatura, umidade relativa e precipitação total no município de Teresina, PI, no período de setembro de 2010 a janeiro de 2011.

\begin{tabular}{cccc}
\hline Mês & $\begin{array}{c}\text { Temperatura } \\
\left({ }^{\circ} \mathbf{C}\right)\end{array}$ & $\begin{array}{c}\text { Umidade relativa } \\
(\mathbf{\%})\end{array}$ & $\begin{array}{c}\text { Precipitação } \\
(\mathbf{m m})\end{array}$ \\
\hline Setembro / 2010 & 29,97 & 51,28 & 0,00 \\
Outubro / 2010 & 29,69 & 60,01 & 0,81 \\
Novembro / 2010 & 29,37 & 63,37 & 1,66 \\
Dezembro / 2010 & 27,71 & 75,41 & 3,77 \\
Janeiro / 2011 & 26,84 & 80,77 & 5,25 \\
\hline
\end{tabular}

O experimento foi conduzido no delineamento em blocos casualizados, com quatro repetições. A parcela foi constituída de três fileiras, cada uma com sete covas, sendo a fileira útil representada por cinco plantas da fileira central. A adubação foi realizada em covas de $5,0 \mathrm{~cm}$ de profundidade, com aplicação de $8 \mathrm{~g}$ de sulfato de amônio $\left(\left(\mathrm{NH}_{4}\right)_{2} \mathrm{SO}_{4}\right), 40 \mathrm{~g}$ de superfosfato simples $\left(\mathrm{P}_{2} \mathrm{O}_{5}\right)$ e $5 \mathrm{~g}$ de cloreto de potássio $\left(\mathrm{K}_{2} \mathrm{O}\right)$, além de um litro de esterco por cova. Para a semeadura utilizou-se três sementes por cova mantendo-se uma planta por cova após o desbaste. A irrigação foi feita por aspersão e para o controle das plantas invasoras realizou-se capina manual ao longo do ciclo da cultura.

Aos 70 dias após o plantio, cinco plantas da fileira útil de cada parcela foram avaliadas visualmente, por três avaliadores. Utilizou-se escala de notas semelhantes à das avaliações de folha destacada, com adaptação para avaliação da planta inteira, da seguinte forma: nota 0 $=$ ausência de sintomas de antracnose na planta; nota $1=$ de 1 a $10 \%$ da planta com sintomas; nota $2=$ de 11 a $25 \%$ da planta com sintomas; nota $3=$ de 26 a $50 \%$ da planta com sintomas; nota $4=$ de 51 a $75 \%$ da planta com sintomas; nota $5=$ de 76 a $100 \%$ da planta com sintomas.

Obteve-se então a média das notas dadas pelos avaliadores para cada planta, e em seguida, a média de todas as plantas da fileira útil. Este dado foi utilizado para representar a média da repetição.

Com base na média das quatro repetições, os acessos foram classificados em cinco categorias quanto à reação a C. truncatum, segundo os mesmos critérios usados para folha destacada e estabelecidos por Belmino (3) para o feijão-caupi.

Os dados das médias das subamostras por repetição, após serem transformados para $\sqrt{\mathrm{x}+1}$, foram submetidos à análise de variância, seguindo-se à comparação entre as médias dos acessos pelo teste de Duncan $(\mathrm{P}<0,05)$. Estas análises foram realizadas com o auxílio do aplicativo Genes (11).

\section{RESULTADOS E DISCUSSÃO}

\section{Experimento 1. Reação de feijão-fava a Colletotrichum} truncatum em folha destacada

A avaliação em folhas destacadas revelou os doze acessos de feijão-fava como suscetíveis a C. truncatum, aos cinco e sete dias após a inoculação (DAI). No entanto, o acesso UFPI 641 apresentou o menor nível de infecção e UFPI 728 o maior, diferindo entre si (Tabela 3), aos sete dias após inoculação.

Aos cinco DAI (Tabela 3) observou-se que dois acessos (UFPI 641 e UFPI 644) comportaram-se como altamente resistentes (AR) e os demais variaram de moderadamente resistente (MR) a altamente suscetível (AS). Por outro lado, aos sete DAI constatou-se aumento na severidade da doença, e em consequência, nove acessos mudaram de classe com redução no grau de resistência e apenas um (UFPI 645) manteve-se como MR aos cinco e sete DAI.

O aumento na severidade da doença, constatado aos sete DAI, pode estar relacionado ao comportamento hemibiotrófico do gênero Colletotrichum, à resistência do hospedeiro e à virulência do isolado $(8,20)$. De acordo com Münch et al. (22), a fase necrotrófica do ciclo do fungo começa entre 48 a 72 horas após a inoculação. Em cultivar suscetível de lentilhas, segundo Chongo et al. (8), o tempo de aparecimento das lesões variou de 72 a 144 horas e de até 14 dias após a inoculação, em cultivar resistente. Carvalho (5), ao avaliar a reação de genótipos de feijão-fava a $C$. truncatum, também constatou aparecimento dos primeiros sintomas aos três DAI do fungo, seguido pelo progresso da doença com queda de folhas ou de um ou mais folíolos. Desta forma, as subamostras que se comportaram como MR (UFPI 641, UFPI 644 e 645) aos sete DAI representam genótipos promissores em programas de seleção que visem incorporar a resistência ao isolado CT4, agente causal da antracnose em feijão-fava.

As médias dos tratamentos sem inoculação do fungo (testemunhas) e dos inoculados para cada acesso revela que a maioria diferiu da testemunha correspondente, nas avaliações realizadas aos cinco e sete DAI (Tabela 4).

A presença de sintomas nas testemunhas dos acessos UFPI 635 e UFPI 643 se deu provavelmente pela ocorrência natural de esporos do fungo no ambiente, o que contribuiu para que esses não diferissem significativamente das testemunhas aos cinco DAI. Aos sete DAI, com o progresso da doença, somente UFPI 643 não diferiu da testemunha.

De acordo com Kamikoga (16), ao avaliar a resistência ao oídio em soja, cultivares que apresentaram poucos sintomas da doença em condições de folhas destacadas e casa de vegetação comportaram-se como resistentes no campo, apresentando pouco ou nenhum sintoma da doença, mesmo na presença de níveis elevados de inóculo do fungo. Assim, as subamostras que ao serem avaliadas em folhas destacadas reagiram como MR ao fungo (Tabela 3 ) ou não diferiram aos sete DAI da testemunha (Tabela 4) podem, em condições de cultivo em campo apresentar uma resistência maior à antracnose. 
Tabela 3. Médias ${ }^{1}$ das notas atribuídas às reações ${ }^{2}$ das subamostras de feijão-fava a Colletotrichum truncatum, avaliadas em folha destacada, aos cinco e sete dias após a inoculação (DAI), em Teresina, PI, 2010/2011.

\begin{tabular}{|c|c|c|c|c|}
\hline Subamostra & Nota aos $5 \mathrm{DAI}^{1}$ & Reação aos 5 DAI $^{2}$ & Nota aos 7 DAI $^{1}$ & Reação aos 7 DAI $^{2}$ \\
\hline UFPI 728 & $4,25 \mathrm{a}$ & AS & $4,75 \mathrm{a}$ & AS \\
\hline UFPI 634 & $2,50 \mathrm{ab}$ & MS & $4,25 \mathrm{ab}$ & AS \\
\hline UFPI 640 & $2,50 \mathrm{ab}$ & MS & $3,50 \mathrm{abc}$ & AS \\
\hline UFPI 642 & $2,50 \mathrm{ab}$ & MS & $4,00 \mathrm{abc}$ & AS \\
\hline UFPI 638 & $2,75 \mathrm{ab}$ & MS & $4,00 \mathrm{abc}$ & AS \\
\hline UFPI 641 & $0,75 \mathrm{~b}$ & $\mathrm{AR}$ & $1,75 \mathrm{c}$ & MR \\
\hline UFPI 632 & $1,75 \mathrm{ab}$ & MR & $2,50 \mathrm{abc}$ & MS \\
\hline UFPI 635 & $2,75 \mathrm{ab}$ & MS & $3,50 \mathrm{abc}$ & AS \\
\hline UFPI 644 & $1,25 \mathrm{~b}$ & $\mathrm{AR}$ & $2,00 \mathrm{bc}$ & MR \\
\hline
\end{tabular}

${ }^{1}$ Médias seguidas da mesma letra, na coluna, não diferem estatisticamente pelo teste Duncan $(\mathrm{P}<0,05)$. ${ }^{1}$ Notas: $0=$ ausência de sintomas; $1=$ traços a $10 \%$ da área foliar infectada; 2 = de 11 a $25 \%$ da área foliar infectada; 3 = de 26 a $50 \%$ da área foliar infectada, sem queda de folíolo; $4=$ de 51 a $75 \%$ da área foliar infectada, sem ou com queda de um dos folíolos; $5=$ de 76 a $100 \%$ da área foliar infectada, sem ou com queda de dois ou três folíolos. ${ }^{2}$ Reações: AR $=$ altamente resistente; $\mathrm{MR}=$ moderadamente resistente; $\mathrm{MS}$ = moderadamente suscetível; $\mathrm{AS}=$ altamente suscetível.

Tabela 4. Médias ${ }^{1}$ das notas atribuídas às reações das subamostras de feijão-fava a Colletotrichum truncatum e das respectivas testemunhas avaliadas em folha destacada, aos cinco e sete dias após a inoculação (DAI), em Teresina, PI, 2010/ 2011.

\begin{tabular}{|c|c|c|c|c|}
\hline \multirow{2}{*}{ Subamostra } & \multicolumn{2}{|c|}{5 DAI } & \multicolumn{2}{|c|}{7 DAI } \\
\hline & Médias das subamostras & Médias das testemunhas & Médias das subamostras & Médias das testemunhas \\
\hline UFPI 728 & $4,25 \mathrm{a}$ & $0,00 \mathrm{~b}$ & $4,75 \mathrm{a}$ & $0,00 \mathrm{~b}$ \\
\hline UFPI 639 & $3,50 \mathrm{a}$ & $0,00 \mathrm{~b}$ & $4,00 \mathrm{a}$ & $0,00 \mathrm{~b}$ \\
\hline UFPI 640 & $2,50 \mathrm{a}$ & $0,00 \mathrm{~b}$ & $3,50 \mathrm{a}$ & $0,00 \mathrm{~b}$ \\
\hline UFPI 642 & $2,50 \mathrm{a}$ & $0,00 \mathrm{~b}$ & $4,00 \mathrm{a}$ & $0,00 \mathrm{~b}$ \\
\hline UFPI 638 & $2,75 \mathrm{a}$ & $0,00 \mathrm{~b}$ & $4,00 \mathrm{a}$ & $0,00 \mathrm{~b}$ \\
\hline UFPI 641 & $0,75 \mathrm{a}$ & $0,00 \mathrm{a}$ & $1,75 \mathrm{a}$ & $0,00 \mathrm{a}$ \\
\hline UFPI 632 & $1,75 \mathrm{a}$ & $0,00 \mathrm{~b}$ & $2,50 \mathrm{a}$ & $0,00 \mathrm{~b}$ \\
\hline UFPI 635 & $2,75 \mathrm{a}$ & $1,00 \mathrm{a}$ & $3,50 \mathrm{a}$ & $1,25 \mathrm{~b}$ \\
\hline UFPI 644 & $1,25 \mathrm{a}$ & $0,00 \mathrm{a}$ & $2,00 \mathrm{a}$ & $0,00 \mathrm{~b}$ \\
\hline UFPI 643 & $2,25 \mathrm{a}$ & $0,25 \mathrm{a}$ & $3,25 \mathrm{a}$ & $0,92 \mathrm{a}$ \\
\hline
\end{tabular}

${ }^{1}$ Médias seguidas de mesma letra, na linha, não diferem da testemunha pelo teste de Dunnett $(\mathrm{P}<0,05) .{ }^{1}$ Notas: $0=$ ausência de sintomas; $1=$ traços a $10 \%$ da área foliar infectada; 2 = de 11 a $25 \%$ da área foliar infectada; 3 = de 26 a $50 \%$ da área foliar infectada, sem queda de folíolo; $4=$ de 51 a $75 \%$ da área foliar infectada, sem ou com queda de um dos folíolos; 5 = de 76 a 100\% da área foliar infectada, sem ou com queda de dois ou três folíolos.

Experimento 2. Reação de feijão-fava a Colletotrichum truncatum em condições de campo

Em condições de campo, os acessos de feijão-fava comportaramse como AR (sete acessos) e MR (cinco acessos) sem diferença significativa entre si no nível de infecção (Tabela 5).

Comparando-se as reações dos acessos de feijão-fava em folhas destacadas (Tabela 3) com as reações a campo (Tabela 5), verificouse variação de comportamento quanto à resistência a antracnose. Em campo, todos os acessos apresentaram nível elevado de resistência variando entre AR a MR, enquanto que em folha destacada, aos sete DAI, a maioria (oito) foi AS e somente três foram MR. Os acessos UFPI 641 e UFPI 644 comportaram-se como MR em folha destacada, aos sete DAI, e a campo. Já o acesso UFPI 645 comportou-se como MR em folha destacada e AR no campo.

Em estudos de avaliações de doenças, vários autores atribuíram às variáveis climáticas as diferentes reações observadas entre os mesmos genótipos, quando submetidos a diferentes condições de cultivo e avaliação $(3,6,14)$. Juliatti et al. (15), em avaliação do sintoma desfolha em alfafa, decorrente da presença de antracnose e mancha de leptosphaerulina, perceberam que neste tipo de avalição deve-se levar em consideração a idade fisiológica das plantas, o microclima e a variabilidade genética. Fatores como temperaturas moderadas, alta umidade e longos períodos de molhamento foliar são citados por outros autores favorecendo o desenvolvimento de fungo do gênero 
Tabela 5. Médias ${ }^{1}$ das notas atribuídas às reações ${ }^{2}$ das subamostras de feijão-fava a Colletotrichum truncatum, avaliadas sob condições de campo, em Teresina, PI, 2010/2011.

\begin{tabular}{ccc}
\hline Subamostra & Nota a campo $^{\mathbf{1}}$ & Reação a campo $^{2}$ \\
\hline UFPI 728 & $1,36 \mathrm{a}$ & $\mathrm{AR}$ \\
UFPI 634 & $1,43 \mathrm{a}$ & $\mathrm{MR}$ \\
UFPI 639 & $1,50 \mathrm{a}$ & $\mathrm{MR}$ \\
UFPI 640 & $1,15 \mathrm{a}$ & $\mathrm{AR}$ \\
UFPI 642 & $1,42 \mathrm{a}$ & $\mathrm{MR}$ \\
UFPI 645 & $0,88 \mathrm{a}$ & $\mathrm{AR}$ \\
UFPI 638 & $1,28 \mathrm{a}$ & $\mathrm{AR}$ \\
UFPI 641 & $1,47 \mathrm{a}$ & $\mathrm{MR}$ \\
UFPI 632 & $1,16 \mathrm{a}$ & $\mathrm{AR}$ \\
UFPI 635 & $1,00 \mathrm{a}$ & $\mathrm{AR}$ \\
UFPI 644 & $1,41 \mathrm{a}$ & $\mathrm{MR}$ \\
UFPI 643 & $1,25 \mathrm{a}$ & $\mathrm{AR}$ \\
\hline CV $(\%)$ & 8,73 & \\
\hline
\end{tabular}

${ }^{1}$ Médias seguidas da mesma letra, na coluna, não diferem estatisticamente pelo teste Duncan $(\mathrm{P}<0,05) .{ }^{1}$ Notas: $0=$ ausência de sintomas; $1=$ traços a $10 \%$ da área foliar infectada; 2 = de 11 a $25 \%$ da área foliar infectada; $3=$ de 26 a 50\% da área foliar infectada, sem queda de folíolo; $4=$ de 51 a $75 \%$ da área foliar infectada, sem ou com queda de um dos folíolos; $5=$ de 76 a 100\% da área foliar infectada, sem ou com queda de dois ou três folíolos. ${ }^{2}$ Reações: $\mathrm{AR}=$ altamente resistente; $\mathrm{MR}=$ moderadamente resistente; $\mathrm{MS}=$ moderadamente suscetível; AS = altamente suscetível.

Colletotrichum $(7,10)$. A ocorrência de baixas precipitação e umidade relativa, bem como altas temperaturas, verificadas durante a realização do experimento no campo, (Tabela 2 ) pode ter contribuído para a baixa incidência da antracnose entre os acessos avaliados.

$\mathrm{O}$ aumento da concentração conidial tem sido relatado como diretamente relacionado ao aumento linear da severidade da antracnose $(3,5,7,17)$. Em folhas destacadas empregou-se uma concentração de $10^{5}$ esporos $/ \mathrm{mL}$, enquanto que em campo as plantas não foram inoculadas artificialmente, mas apenas plantadas em área com histórico de ocorrência natural de antracnose e, provavelmente houve baixo potencial de inóculo do fungo. Este fato pode também ter contribuído para a diferença constatada entre as reações dos acessos em folhas destacadas e a campo.

Segundo Dhingra \& Sinclair (13), a ação da luz também é um fator que tem influência na germinação de esporos de patógenos, podendo inibir ou estimulá-la. Manandhar et al. (18) verificaram que a severidade e sobrevivência de C. truncatum foi maior na ausência de luz pelo fato de nessas condições haver redução da fotossíntese e enfraquecimento da planta hospedeira. Em campo, as plantas avaliadas foram submetidas à incidência direta do sol e longos períodos sem chuva (Tabela 2). Nessas condições, com a diminuição na umidade na superfície foliar, o desenvolvimento do patógeno e, consequentemente, o aparecimento da doença, foi reduzido.

\section{REFERÊNCIAS BIBLIOGRÁFICAS}

1. Azevedo, J.N.; Franco, L.J.D.; Araújo, R.O.C. Composição química de sete variedades de feijão-fava. Teresina: Embrapa Meio-Norte, 2003, comunicado técnico, n.152, 4p.
2. Assunção I. P.; Nascimento L.D.; Ferreira, M.F; Oliveira, F.J.; Michereff, S.J.; LIMA,G.S.A. Reaction of faba bean genotypes to Rhizoctonia solani and resistance stability. Horticultura Brasileira, Bahia, v.29, n. 1, p. 492-497, 2011.

3. Belmino, C.S. Resistência do feijão-caupi a Colletotrichum truncatum. 2004. 64f. Tese (Doutorado em Fitopatologia) - Universidade Federal de Viçosa, Viçosa.

4. Brammer, S.P. Mapeamento de genes de resistência parcial à ferrugem-da-folha em cultivares brasileiras de trigo (Triticum aestivum L. em Thell). 2000. 105f. Tese (Doutorado em Genética) - Universidade Federal do Rio Grande do Sul, Porto Alegre.

5. Carvalho, E.M.S. Antracnose em feijão-fava: caracterização do agente causal e reação de genótipos a Colletotrichum truncatum. 2009. 69f. Tese (Doutorado em Agronomia - Produção Vegetal) - Universidade Estadual Paulista "Júlio de Mesquita Filho", Jaboticabal.

6. Chala, A.; Brurberg, M.B.; Tronsmo, A.M. Incidence and severity of sorghum anthracnose in Ethiopia. Plant Pathology Journal, Suwon, v.9, n. 1, p. $23-30,2010$.

7. Chongo, G.; Bernier, C.C. Effects of host, inoculum concentration, wetness duration, growth stage, and temperature on anthracnose of lentil. Plant Disease, St. Paul, v.84, n.5, p.544-548, 2000.

8. Chongo, G.; Gossen, B.D.; Bernier, C.C. Infection by Colletotrichum truncatum in resistant and susceptible lentil genotypes. Canadian Journal Plant Pathology, Ontario, v.24, n.1, p.81-85, 2002.

9. Costa, A.F. Antracnose da fava (Phaseolus lunatus L.) no Nordeste causada por Colletotrichum dematium f. truncata. Fitopatologia Brasileira, Brasília, v.11, supl., p.315, 1986.

10. Costa, I.F.D.; Balardin, R.S.; Medeiros, L.A.M.; Lenz, G.; Gulart, C.A.; Zemolin, C.R.; Silva, T.M.B. Reação de germoplasma comercial de soja a Colletotrichum truncatum. Tropical Plant Pathology, Brasília, v.34, n.1, p.47-50, 2009.

11. Cruz, C.D. Programa Genes: aplicativo computacional em genética e estatística. Versão 2007.0.0. Viçosa, MG: Universidade Federal de Viçosa, 2006. Disponível em <www.ufv.br/dbg/genes/genes.htm>. Acesso em: 18 abr. 2011.

12. Damm, U.; Woudenberg, J.H.C.; Cannon, P.F.; Crous, P.W. Colletotrichum species with curved conidia from herbaceous hosts. Fungal Diversity, Chiang Mai, v.39, p. 45-87, 2009.

13. Dhingra, O.D.; Sinclair, J.B. Basic Methods in Plant Pathology. 2.ed. Boca Raton: Lewis Publishers, 1995. 434p.

14. Garcia, A.; Souza, P.E.; Pozza, E.A.; Santos, F.S. Influência das variáveis ambientais no progresso da antracnose do feijoeiro e eficiência de tiofanato metílico + clorotalonil no controle da doença. Ciência Agrotécnica, Lavras, v.31, n.6, p.1709-1715, 2007.

15. Juliatti, F.C.; Pimenta, F.A.; Martins, J.A.S.; Pozza, E.A.; Silva, S.A.; Rey, M.S.; Santos, R.R. Resistência de cultivares de alfafa à antracnose e à mancha de Leptosphaerulina em Uberlândia-MG. Summa Phytopathologica, Botucatu, v. 37, n. 4, p. 169-173, 2011.

16. Kamikoga, A.T.M. Método da folha destacada para avaliar resistência da soja ao oídio. 2001. 98f. Tese (Doutorado em Agronomia - Produção Vegetal) - Universidade Federal do Paraná, Curitiba.

17. Maia, C.B.; Santos, G.R.; Sousa, S.C. Ocorrência de Colletotrichum truncatum em plantas de Phaseolus lunatus no estado do Piauí. Fitopatologia Brasileira, Brasília, v.32, supl., p.211, 2007.

18. Manandhar, J.B.; Hartman, G.L.; Sinclair, J.B. Soybean germplasm evalu† ation for resistance to Colletotrichum truncatum. Plant Disease, St. Paul, v.72, n.1, p.56-59, 1988.

19. Martins, I.; Peixoto, J.R.; Junqueira, N.V.T.; Mello, S.C.M. Reação de genótipos de maracujazeiro-amarelo ao Colletotrichum gloeosporioides. Revista Brasileira de Fruticultura, Jaboticabal, v.30, n.3, p.639-643, 2008.

20. Medeiros, L.A.M.; Balardin, R.S.; Costa, I.F.D.; Gulart, C.A.; Lenz, G. Reação de germoplasma crioulo de feijoeiro a Colletotrichum lindemuthianum. Tropical Plant Pathology, Brasília, v.33, n.4, p.273-280, 2008.

21. Mendes, B.M.J.; Bergamin Filho, A. Adaptação da técnica da cultura de folha destacada para a quantificação dos parâmetros epidemiológicos monocíclicos da ferrugem do feijoeiro (Uromyces phaseoli var. typica). Fitopatologia Brasileira, Brasília, v.11, p.103-114, 1986.

22. Münch, S.; Lingner, U.; Floss, D.S.; Ludwig, N.; Sauer, N.; Deising, H.B. The hemibiotrophic lifestyle of Colletotrichum species. Journal of Plant Physiology, Amsterdam, v.165, n.1, p.41-51, 2008.

23. Oliveira, A.P.; Alves, E.U.; Alves, A.U.; Dornelas, C.S.M.; Silva, J.A.; Porto, 
M.L.; Alves, A.V. Produção de feijão-fava em função do uso de doses de fósforo em um Neossolo Regolítico. Horticultura Brasileira, Brasília, v.22, n.3, p.543-546, 2004.

24. Papp, C.S. Highlights. Cooperative Plant Pest Report for California, Califórnia, 26, set, 1980. Bean Anthracnose, v.3, n.39, p.1-7.

25. Paula Júnior, T.J.; Silva, M.B.; Vieira, R.F. Doenças causadas por fungos em hortaliças leguminosas. Informe Agropecuário, Belo Horizonte, v.17, n.182, p.63-71, 1995.

26. Peixoto, N.; Moraes, E.A.; Monteiro, J.D.; Thung, M.D.T. Seleção de linhagens de feijão-vagem de crescimento indeterminado para cultivo no Estado de Goiás. Horticultura Brasileira, Brasília, v.19, n.1, p.85-88, 2001.

27. Queiroz, M.A.; Lopes, M.A. Importância dos recursos genéticos para o agronegócio. In: NASS, L. L. Recursos genéticos vegetais. Brasília: Embrapa Recursos Genéticos e Biotecnologia, 2007, p. 281-305.

28. Rava, C.A.; Purchio, A.F.; Sartorato, A. Caracterização de patótipos de Colletotrichum lindemuthianum que ocorrem em algumas regiões produtoras de feijoeiro comum. Fitopatologia Brasileira, Brasília, v.29, n.2, p.167-172, 1994.

29. Sartorato, A. Antracnose. In: Zimmermann, M.J.O.; Rocha, M.; Yamada, T. Cultura do feijoeiro: fatores que afetam a produtividade. Piracicaba, Potafos: 1988, p. 457-477.

30. Silva, C.A.; Abreu, A.F.B.; Ramalho, M.A.P. Associação entre arquitetura de planta e produtividade de grãos em progênies de feijoeiro de porte ereto e prostrado. Pesquisa Agropecuária Brasileira, Brasília, DF, v.44, n.12, p.1647-1652, 2009.

31. Silva J.A.; Oliveira, M.G.; Souza, L.T.;Assunção, I.P.; Lima, G.A.; Michereff, S.J. Reação de genótipos de feijão-fava a Sclerotium rolfsii. Horticultura Brasileira, Bahia, v.32, n.1, p. 98-101, 2014.

32. Sponholz, C.; Freire Filho, F.R.; Maia, C.B.; Ribeiro, V.Q.; Cardoso, M.O. Reação de genótipos de feijão-caupi a Colletotrichum truncatum. Teresina: Embrapa Meio-Norte, Boletim de Pesquisa e Desenvolvimento, n.65, 2006. $18 \mathrm{p}$.

33. Vieira, R.F. A cultura do feijão-fava. Informe Agropecuário, Belo Horizonte, v.16, n.174, p.30-37, 1992. 